\title{
Alt Ekstremite Ampütelerinde Vücut İmajı Algısı ve Yaşam Memnuniyeti İlişkisi
}

The Relationship between Body Image Perception and Life Satisfaction in Individuals with Lower Extremity Amputation

\author{
Orkun Tahir ARAN ${ }^{1}$, Merve Şuay ÜÇGÜL ${ }^{2}$, Gamze EKiCi ${ }^{3}$ \\ ${ }^{1}$ Dr. Fzt., Hacettepe Üniversitesi, Sağlık Bilimleri Fakültesi, Ergoterapi Bölümü, Ankara \\ ${ }^{2}$ Uz. Fzt., İstanbul Üniversitesi, Sağlık Bilimleri Fakültesi, Fizik Tedavi ve Rehabilitasyon Bölümü, İstanbul \\ ${ }^{3}$ Prof. Dr., Hacettepe Üniversitesi, Sağlık Bilimleri Fakültesi, Ergoterapi Bölümü, Ankara
}

\section{öz}

\begin{abstract}
Amaç: Çalışma, alt ekstremite ampütelerinde yetişkin bireylerin vücut imajı algısı ile yaşam memnuniyeti arasındaki ilişkiyi incelemek amacıyla planlandı. Gereç ve Yöntem: Araştırmaya 57 (14 kadın, 43 erkek) alt ekstremite ampütesi edildi. Çalışmaya dahil edilen bireylerin cinsiyeti, yaşı, beden kütle indeksi, ampütasyon süresi ve tarafı kaydedildi. Katılımcılarda yaşam memnuniyet düzeyi "Yaşam Memnuniyeti Skalası" (YMS) ile, vücut imajı algısı ise "Ampüte Vücut İmajı Skalası" (AViS) ile değerlendirildi. Sonuçlar: Çalışmaya yaş ortalamaları $39,15 \pm 11,95$ yıl olan 29 sağ, 23 sol ve 5 bilateral alt ekstremite ampütasyonlu birey dahil edildi. Katılımcıların YMS ortalama skoru 25,94 $\pm 5,77$, AViS

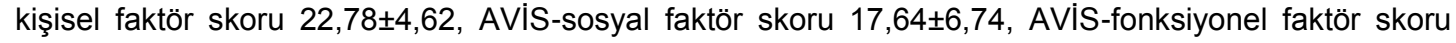
$14,59 \pm 10,67$ ve AVis toplam skoru $52,80 \pm 10,73$ olarak bulundu. YMS toplam skoru ile AVis-kişisel faktör $(p=0,012, r=-0,330)$, AViS-sosyal faktör $(p=0,003, r=-0,393)$, AViS-fonksiyonel faktör $(p=0,044$, $r=-0,268)$ ve AViS-toplam skoru $(p=0,001, r=-0,515)$ arasında istatistiksel olarak anlamlı negatif yönde ilişki bulunmuştur. Tartışma: Çalışmadan elde edilen veriler aracılığıyla ampütelerin vücut imajı algısı ile yaşam memnuniyetleri arasında anlamlı ilişki ortaya koyulmuştur. Ampüte rehabilitasyonunda, bireyin hayata bağlanmasının ve katılımının desteklenmesi için vücut algııının üzerinde durulması gerektiği düşünülmektedir.
\end{abstract}

Anahtar Kelimeler: Ampütasyon; Vücut imajı; Yaşam memnuniyeti

\section{ABSTRACT}

Purpose: Purpose: The study was planned to investigate the relationship between body image perception and life satisfaction of adult individuals with lower limb amputation. Material and Methods: Fifty-seven (14 female, 43 male) individuals with lower limb amputation were included in the study. The participants' gender, age, body mass index, amputation duration and side were recorded. Participants' life satisfaction statuses were assed by Satisfaction with Life Questionnaire (SWLQ) and body image perception were assessed by the "Amputee Body Image Scale" (ABIS). Results: The study included 29 right, 23 left, and 5 bilateral lower extremity amputee (mean age $39.15 \pm 11.95$ years). Individuals had SWLQ mean score of $25.94 \pm 5.77$, ABIS personal factor score of $22.78 \pm 4.62$, ABIS-social factor score of $17.64 \pm 6.74$, ABIS-functional factor score of $14.59 \pm 10.67$ and ABIS total score of $52.80 \pm 10.73$. There were statistically significant negative correlations between SWLQ total score and ABIS-personal factor $(p=0.012, r=-0.330)$, ABIS-social factor $(p=0.003, r=-0.393)$, ABIS- functional factor $(p=0.044, r=-$ $0.268)$ and ABIS-total score $(p=0.001, r=-0.515)$. Discussion: Through the data obtained from study, significant relationship was found between the body image perception and life satisfaction. In amputee rehabilitation, it is thought that body perception must be emphasized in order to support the attachment and participation to life.

Key Words: Amputation; Body image; Life satisfaction 
Ampütasyon, bireyin yaşam kalitesini, otonomisini ve iyi-olma durumunu etkileyebilen ciddi tıbbi ve psiko-sosyal bir durumdur (Ahmad, Thomas, Gill ve ark, 2014). Bu nedenle, bireyde vücut imajı algısı bozuklukları gibi ruhsal sorunların da görülebileceği belirtilmektedir (Gilg, 2016). Ampütasyon sonrası gelişen vücut imajı algısındaki değişiklikler, yaşam memnuniyeti düzeyi ve ruhsal durum bireyin protezi kabulünü, rehabilitasyonun başarısını ve protezle yaptığı tüm günlük yaşam aktivitelerini etkilemektedir (Holzer, Sevelda, Fraberger ve ark, 2014; Pedlow, Cormier, Provost ve ark, 2014).

Bireyin fiziksel görünümünü algılamasına vücut algısı denir (Tylka \& Wood-Barcalow, 2015). Başka bir tanımlamaya göre ise vücut imajı, bireylerin fiziksel benliklerinin zihinsel bir resmi ve diğerlerinin onların fiziksel durumlarını nasıl gördüğünün algısı olarak tanımlanmıştır (Gilg, 2016). Yapılan araştırmalarda ampütasyon sonrası bireylerin aktivitelere katılımında ve öz-benlik algısında yetersizlik; yaşam kalitesinde, vücut imajı algısında ve bunu tanımlamada bozulmalar olduğu gösterilmiştir (Holzer ve ark, 2014; Peroni, Cornaggia, Cerri ve ark, 2017; Shields, Thorp, Hendry ve ark, 2015).

Son yıllarda literatürde vücut imajı algısı değerlendirmeleri kapsamlı bir yer tutmaktadır. Vücut İdrak Ölçümü (Measure of Body Apperception) (Peroni ve ark, 2017), Vücut Takibi (Body Tracing ) (Breakey, 1997), Çok Boyutlu ÖzVücut İlişkisi Ölçeği (Multidimensional Body-Self Relations Questionnaire) (Cash, 2015), Vücut Algısı Ölçeği (Hovardaoğlu, 1993), Vücut Memnuniyeti Ölçeği (Bakalım \& Taşdelen-Karkçay, 2016) araştırmalarda sık kullanılan değerlendirme araçlarına örnektir. Bu ölçeklerden Vücut Algısı Ölçeği'nin ve Vücut Memnuniyeti Ölçeği'nin Türkçe geçerlilik ve güvenilirlik çalışmaları yapılmıştır. Bahsedilen ölçeklerden farklı olarak Ampüte Vücut İmajı Skalası (AVIS) ampütelere özel olarak geliştirilmiştir. Daha önce de belirtildiği gibi, ampütasyon nedeniyle vücut imajı algısında olan değişiklikler hem fiziksel hem de psiko-sosyal açıdan bireyin tüm yaşamını etkileyebilmektedir.

Yaşam memnuniyeti, bireyin içinde bulunduğu hayat şartlarından hoşnut olması ve yaşama sevincine sahip olmasıdır. Başka bir deyişle, bireyin kendi seçtiği kriterlere göre yaşamının niteliği hakkındaki genel değerlendirmesi olarak ele alınır (Civitci, 2015; Ülker Tümlü \& Recepoğlu, 2013). Ampütasyon olan bireyin yaşam tarzındaki değişiklikler, fiziksel fonksiyonlardaki bozuklukların varlığı bireyin yaşam memnuniyeti düzeyini etkileyebilir.

Alt ekstremite fonksiyonel olarak hem stabilite, hem de mobilite açısından bireyin yaşamındaki tüm performans alanları üzerinde etkilidir. Alt ekstremite gibi önemli bir uzvun, unilateral veya bilateral kaybı sonucunda yaşanabilecek vücut imajı algısındaki bozukluklar üzerine kısıtlı sayıda çalışmalar olduğu görülmüştür (Anderson, Roubinov, Turner ve ark, 2017; Ebrahimzadeh, Moradi, Bozorgnia ve ark, 2016; Pirowska, Wloch, Nowobilski ve ark, 2014). Özellikle alt ekstremite ampütelerinin yaşamdaki başarısını ve motivasyonunu etkileyebilecek yaşamdan aldığı tatmini inceleyen çalışma sayısı oldukça azdır (Breakey, 1997; Holzer ve ark, 2014). Bu çalışma alt ekstremite ampütelerinin vücut imajı algısı ile yaşam memnuniyeti arasındaki ilişkiyi incelemek amacıyla planlanmıştır.

\section{GEREÇ VE YÖNTEM}

Çalışmamız 2016-2017 yılları arasında Hacettepe Üniversitesi, Sağlık Bilimleri Fakültesi, Ergoterapi Bölümü Eğitim ve Araştırma Ünitelerinde gerçekleştirildi. Çalışmaya protez kullanan 52 unilateral (22 diz üstü, $30 \mathrm{diz}$ altı ampüte), 5 bilateral (3 bireyin diz altı ve diz üstü, 2 kişi bilateral diz altı ampüte) gönüllü ampüte dahil edildi. Çalışmaya katılan herkese çalışma hakkında bilgi verilip, dahil edilen bireylerden Helsinki deklerasyonuna uygun olarak sözlü onam alındı.

Çalışmaya dahil edilme kriterleri;

- Bireylerin en az 1 yıldır ampütasyonu olması

- En az bir taraf alt ekstremitesinde ampütasyonunun olması,

- Ampütasyon sonrası hemen protez kullanmaya başlamış olması,

- Çalışmaya katılmaya gönüllü olmaları,

Çalışmaya dahil edilmeme kriterleri;

- Bireylerde eşlik eden ruhsal, fiziksel ya da nörolojik kronik bir hastalığın olması,

- Okuma yazma bilmemesi olarak belirlenmiştir.

Çalışmaya dahil edilen bireylerin cinsiyeti, yaşı, beden kütle indeksi, ampütasyon süresi ve tarafı kaydedildi. Katılımcılarda yaşam memnuniyet düzeyi "Yaşam Memnuniyeti Skalası" (YMS) ile, vücut imajı algısı ise "Ampüte Vücut İmajı Skalası" (AVis) ile değerlendirildi.

Ampüte Vücut İmajı Skalası, bir ampütenin kendi vücut deneyimiyle ilgili algı ve duygularını sorgulayan 20 maddeden oluşur. AVIS, kişisel, sosyal ve fonksiyonel faktörler olan üç farklı alanda ampüte beden imajını inceler (Breakey, 1997). 
Katılımcılardan soruları 1 (zamanın hiçbiri) ile 5 (diğer zaman) arasında yanıtlamaları istenir ve 20 maddenin toplanmasıyla ölçeğin toplam puanı elde edilir. Bu ölçekte, yüksek puanlar yüksek vücut imajı bozulmasını belirtir (Bayramlar, Bumin, Yakut ve ark, 2007; Safaz, Yilmaz, Goktepe ve ark, 2010). Bumin ve diğerlerinin çalışmasıyla ölçeğin Türkçe geçerlilik ve güvenilirliği $(0,83$ Cronbach alfa ve 0.93 ICC) gösterilmiştir (Bumin, Bayramlar, Yakut ve ark, 2009).

Yaşam Memnuniyeti Skalası ideallere yakınlık, yaşam koşulları, tatmin, geçmişte yaşadıkları ve yaşamına dair değiştirmek istediği durumların varlığını değerlendirmektedir. Yaşam memnuniyeti, 5 soruya verilen 1-7 arasında puan ile değerlendirilir (7: kesinlikte katılıyorum, 6: katılıyorum, 5: çok az katılıyorum, 4: ne katılıyorum ne katılmıyorum, 3: biraz katılmıyorum, 2: katılmıyorum, 1: kesinlikle katılmıyorum). Sorulara verilen puanların toplamına göre bireyin memnuniyet derecesi belirlenmektedir (31-35 puan: çok memnun, 26-30 puan: memnun, 21-25 puan: kısmen memnun, 20 puan: kararsız, 15-19 puan: kısmen memnuniyetsiz, 10-14 puan: memnuniyetsiz, 5-9 puan: çok memnuniyetsiz olarak tanımlanmaktadır). Bireyin verdiği cevaplara göre puan yükseldikçe, memnuniyet seviyesi de artış göstermektedir (Diener, Emmons, Larsen ve ark, 1985). Durak ve diğ. tarafından Türkçe geçerlilik ve güvenilirlik çalışması yapılmıştır (Cronbach alpha $=0,82)$ (Durak, Senol-Durak, \& Gencoz, 2010).

\section{Istatistiksel Analiz}

İstatistiksel analizler "IBM SPSS for Windows" versiyon 21 yazılımı kullanılarak yapılmıştır. Görsel ve analitik yöntemlerle verilerin normal dağılıma uygunluğu incelenmiştir. Tanımlayıcı istatistiklerde nümerik değişkenler için ortalama ve standart sapma, ordinal değişkenler için frekans tablosu olarak verilmiştir. Veriler normal dağılım göstermediği için bireylerin vücut imajı algıları ile yaşam memnuniyeti durumları arasındaki ilişki Spearman Korelasyon Analizi ile değerlendirilmiştir. İstatistiksel anlamlılık değeri \%95 $(p<0.05)$ olarak kabul edilmiştir.

\section{SONUÇLAR}

Çalışmamız için toplam 68 ampüteye ulaşıldı. Bu bireylerden 2'sinde eşlik eden üst ekstremite ampütasyonu olması, 4'ünde 1 yıldan daha kısa süredir ampütasyon olması sebebiyle, 5'inde ise ulaşım problemleri ve değerlendirmeye katılmayı kabul etmeme durumlardan dolayı çalışma, 57 ampüte ile tamamlanmıştır. Bireylerin demografik özellikleri, ampütasyon süreleri ve tarafları ve beden kütle indeksleri (BKI) Tablo 1'de verilmiştir. Vücut imajı algıları ve yaşam memnuniyet durumları Tablo 2 gösterilmiştir. Yapılan analizlerde yaşam memnuniyeti ile vücut imajı algısı alt parametreleri arasında negatif yönde zayıf kuvvette ve vücut imajı algısı toplam puanı ile yaşam memnuniyeti düzeyleri arasında ise negatif yönde orta kuvvette istatistiksel olarak anlamlı ilişkiler olduğu görülmüştür $\quad(p<0.05) \quad$ (Tablo 3$)$.

Tablo 1. Katılımcıların demografik bilgileri, ampütasyon taraf ve süreleri $(n=57)$

\begin{tabular}{lrl}
\hline & $\mathbf{n}$ & $\mathbf{( \% )}$ \\
\hline Cinsiyet (Kadın / Erkek) & $14 / 43$ & $(24.6 / 75.4)$ \\
\hline Ampütasyon tarafı & 29 & $(50,8)$ \\
$\quad$ Sağ & 23 & $(40,4)$ \\
Sol & 5 & $(8,8)$ \\
$\quad$ Bilateral & $\mathbf{X} \pm \mathbf{S S}$ \\
\hline & $39,15 \pm 11,95$ \\
\hline Yaş (yıl) (min.:13; maks.:67) & $26,28 \pm 4,38$ \\
\hline Beden kütle indeksi $\left(\mathrm{kg} / \mathrm{m}^{2}\right)($ min.:17; maks.:35) & $14,59 \pm 10,67$ \\
\hline Ampütasyon süresi (yıl) (min.:1; maks.:40)
\end{tabular}


Tablo 2. Ampüte Vücut İmajı Skalası ve Yaşam Memnuniyeti ortalama değerleri $(n=57)$

\begin{tabular}{ll}
\hline & X \pm SS \\
\hline Yaşam Memnuniyet Skalası (min.:13; maks.:45) & $25,94 \pm 5,77$ \\
AViS-kişisel faktör (min.:13; maks.:33) & $22,78 \pm 4,62$ \\
AViS-sosyal faktör (min.:6; maks.:33) & $17,64 \pm 6,74$ \\
AViS-fonksiyonel faktör (min.:4; maks.:19) & $14,59 \pm 10,67$ \\
AVis-toplam (min.:25; maks.:80) & $52,80 \pm 10,73$ \\
\hline
\end{tabular}

AVIS: Ampüte Vücut İmajı Skalası

Tablo 3. Vücut İmajı Algısı ile Yaşam Memnuniyeti arasındaki ilişki (n=57)

\begin{tabular}{|c|c|}
\hline & Yaşam Memnuniyet Skalası \\
\hline \multirow[t]{2}{*}{ AViS-kişisel faktör } & $r=-0,330^{*}$ \\
\hline & $p=0,012$ \\
\hline \multirow[t]{2}{*}{ AVIS-sosyal faktör } & $r=-0,393^{\star *}$ \\
\hline & $p=0,003$ \\
\hline \multirow[t]{2}{*}{ AVis-fonksiyonel faktör } & $r=-0,268^{*}$ \\
\hline & $p=0,044$ \\
\hline \multirow[t]{2}{*}{ AVis-toplam } & $r=-0,515^{\star \star}$ \\
\hline & $p=0,001$ \\
\hline
\end{tabular}

\section{TARTIŞMA}

Ampütelerin vücut imajı algısı ile yaşam memnuniyeti arasındaki ilişkinin incelendiği çalışmada anlamlı ilişkiler ortaya koyulmuştur.

Uluslararası Fonksiyonellik, Özür ve Sağlık Sınıflandırılması'na (ICF) göre mobilite aktivite ve katılımın en önemli anahtar faktörlerinden birisidir (World Health Organization, 2001). Miller ve diğerleri, mobilite kaybının alt ekstremite ampütelerinde en belirgin fonksiyonel limitasyonlardan birisi olduğunu belirtmişlerdir (Miller, Deathe, \& Speechley, 2001). Alt ekstremite ampütelerinde yapılan bu çalışmada da bireylerin fonksiyonelliğinin etkilendiği görülmüştür. Buna bağlı olarak, bireyler yaşamlarında zorluklar yaşadıklarını sözel olarak ifade etmişlerdir. Ampütasyon travmatik bir cerrahi olup, nedenine bağlı olmaksızın bireylerin günlük yaşamının her alanına büyük çaplı değişiklikler getirir. Genel olarak, alt ekstremite ampütasyonunu takiben görülen mobilite kaybı, bireylerin sosyal rollere katılımlarını, günlük yaşam aktivitelerinde başarılarını etkilemektedir. Özellikle bireyin sosyal aktivitelere katılması ve toplumsal rollerini yerine getirmesi gibi aktivitelere katılımın azalması, travmanın boyutunu artırmaktadır (Sinha \& Van Den Heuvel, 2011; Zidarov, Swaine, \& Gauthier-
Gagnon, 2009).

Uzuv kaybı yaşayan bireylerin vücut imajı algılarını etkileyebilen psiko-sosyal durum değişiklikleri olabileceği belirtilmiştir (Mayer, Kudar, Bretz ve ark, 2008). Yapılan çalışmalarda, ampütelerin vücut imajı algılarının etkilendiği gösterilmiştir (Akkaya, Atalay, Selcuk ve ark, 2011; Bayramlar ve ark, 2007; Breakey, 1997; Gilg, 2016). Çalışmamızda da bu bilgileri destekleyecek şekilde katılımcıların vücut imaj algılarında değişiklikler gözlemlenmiştir. Bireyin vücut imajı algısındaki bozulmalar, sosyal medyada ve toplumun çoğunluğunun kabul ettiği estetik algısına da uymamasından dolayı ampütelerin yaşamlarını fiziksel, sosyal ve psikolojik olarak etkileyebileceği belirtilmiştir (Ching, Thoma, McCabe ve ark, 2003; Thompson, Heinberg, Altabe ve ark, 1999). Bütün bunlara ek olarak, ampütasyonun bireyin kendisini yetersiz hissettirebileceğini ve oluşan yeni vücut imajı kişinin vücut imajı algısına uymayabileceği söylenmiştir (Alagöz, Başterzi, Uysal ve ark, 2003; Novotny, 1986). Ayrıca, vücut imajı algısındaki bozuklukların bireylerin dahil olduğu aktiviteleri etkilediği gösterilmiştir (Wetterhahn, Hanson, \& Levy, 2002). Çalışmamızda katılımcıların AVis toplam skorlarının yarı yarıya etkilenmiş olduğu görülmektedir. Bunun yanında, araştırmamızda elde edilen bulgular, literatürdeki çalışmalarla 
benzer sonuçlar göstermiş olup bu bulguları destekler niteliktedir. Ayrıca katılımcıların özellikle fonksiyonel faktörlerinin kişisel faktörle kıyaslandığında daha az etkilenmesinin yaşam memnuniyeti ile ilişkisinin düşük düzeyde olmasına neden olduğu söylenebilir.

Literatürde, ampütasyon sonrası bireylerin yaşam memnuniyeti düzeyini inceleyen çalışma sayısı oldukça azdır (Breakey, 1997; Holzer ve ark, 2014). Holzer ve diğerlerinin çalışmasında kullanılan yaşam memnuniyet düzeyi ölçümü, kişinin vücut imajı bütünlüğü ile ilgili memnuniyetini ölçerken çalışma içerisinde bu durum yaşam memnuniyeti terminolojisi olarak anlatılmıştır (Holzer ve ark, 2014). Bireyin yaşam kalitesini algılama düzeyi ve nasıl gördüğü, yaşam memnuniyeti düzeyini verir (Diener ve ark, 1985). $\mathrm{Bu}$ tanımdan dolayı, bireylerde yaşam memnuniyetinin ayrı olarak değerlendirilmesi gerektiği ve ampütelerin psiko-sosyal durumlarını inceleyen çalışmalarda, yalnızca yaşam kalitesinin değerlendirilmesinin yeterli olmayabileceği düşünülmektedir. Yaşam memnuniyeti algısının, yaşamdan "kısmen memnun" olarak bulunduğu çalışmamızın, bu yönü ile literatürde bulunan diğer çalışmalardan farklı olduğu gözlemlenmektedir.

Araştırmamızda, ampütelerin vücut imajı algıları ve yaşam memnuniyeti düzeyleri arasında anlamlı ilişki bulunmuştur. Literatürde her iki değişkenin birbirine olan etkisini inceleyen yalnızca bir çalışmaya rastlanmıştır (Breakey, 1997). Bu çalışmadaki sonuçlar, çalışmamız ile örtüşmekte olup; ampütelerin vücut imajı algı düzeyleri azaldıkça, yaşam memnuniyeti düzeylerinin de azaldığı gösterilmiştir.

Çalışmamıza dahil edilen bireylerin hem tek taraflı hem de bilateral ampütasyonu bulunması ve bu ampütasyonların farklı seviyelerden olması, ampütasyon nedenlerinin ve protez tiplerinin sorgulanmamış olması, vücut imajı algısının etkilenme düzeyinin belirlenebilmesi için kontrol grubunun olmaması, yaş aralığının ve ampütasyon cerrahi sürelerinin geniş aralıkta olması gibi özellikler, çalışmanın limitasyonları olarak düşünülmektedir. Farklı cinsiyetlerin çalışmaya dahil edilmesi, kadınların ve erkeklerin vücut imajı algısının farklı olabilmesi nedeniyle çalışmanın sonuçlarını etkileyebilecek bir limitasyon olarak kabul edilmektedir.

Yaşam memnuniyetini kişinin idealleri, yaşam koşulları, istekleri ve bunlardan tatmin olma konusundaki kişinin algısı oluşturur (Durak ve ark, 2010). Bu çalışmada, ampütasyon sonrası fonksiyonellik, duyu ve vücut imajındaki kayıp bireyin yaşamında pek çok alanı etkileyerek dolayısı ile yaşam memnuniyeti düzeyinin de etkilendiği ortaya koyulmuştur. Ampütelerle çalışırken, rehabilitasyon ekibinin bu değişkenler arasındaki ilişkileri göz önüne alarak tedavi planlamasını yapması gerektiği, özellikle kişinin yaşama tutunması ve hayata tekrar katılımının en iyi şekilde sağlanabilmesi için bireyin vücut imajı algısının, üzerinde durulması gereken önemli bir konu olduğu görülmüştür. Bütün bu bulgulara karşın, vücut imajı algısı ve yaşam memnuniyeti arasındaki ilişkiyi incelerken çalışmamızın limitasyonları dikkate alınarak, kontrol grubunun da dahil edildiği çalışmaların planlanması önerilmektedir.

\section{Kaynaklar}

Ahmad, N., Thomas, G. N., Gill, P., Chan, C., \& Torella, F. (2014). Lower limb amputation in England: prevalence, regional variation and relationship with revascularisation, deprivation and risk factors. A retrospective review of hospital data. Journal of the Royal Society of Medicine, 107(12), 483-489.

Akkaya, N., Atalay, N. S., Selcuk, S. T., Akkaya, S., \& Ardic, F. (2011). Impact of body image on quality of life and mood in mastectomized patients and amputees in Turkey. Asian Pac J Cancer Prev, 12(10), 2669-2673.

Alagöz, M. Ş., Başterzi, A. D., Uysal, A. Ç., Tüzer, V., Ünlü, R. E., Şensöz, Ö.,\& et al. (2003). The psychiatric view of patients of aesthetic surgery: self-esteem, body image, and eating attitude. Aesthetic plastic surgery, 27(5), 345348.

Anderson, D. R., Roubinov, D. S., Turner, A. P., Williams, R. M., Norvell, D. C., \& Czerniecki, J. M. (2017). Perceived social support moderates the relationship between activities of daily living and depression after lower limb loss. Rehabil Psychol, 62(2), 214.

Bakalım, O., \& Taşdelen-Karkçay, A. (2016). Body Appreciation Scale: evaluation of the factor structure and psychometric properties among male and female Turkish university students. Mersin Üniversitesi Eğitim Fakültesi Dergisi, 12(1), 410-422.

Bayramlar, K., Bumin, G., Yakut, Y., \& Şener, G. (2007). Ampute Vücut İmajı Ölçeği (Amputee Body Image ScaleABIS) Türkçe uyarlamasının geçerliği. Fizyoterapi ve Rehabilitasyon, 18(2), 79-83.

Breakey, J. W. (1997). Body Image: The Lower-Limb Amputee. J Prosthet Orthot, 9(2), 58-66.

Bumin, G., Bayramlar, K., Yakut, Y., \& Sener, G. (2009). Cross cultural adaptation and reliability of the Turkish version of Amputee Body Image Scale (ABIS). J Back Musculoskelet Rehabil, 22(1), 11-16.

Cash, T. F. (2015). Multidimensional Body-Self Relations Questionnaire (MBSRQ). Encyclopedia of Feeding and Eating Disorders (pp. 1-4). Springer.

Ching, S., Thoma, A., McCabe, R. E., \& Antony, M. M. (2003). Measuring outcomes in aesthetic surgery: a 
comprehensive review of the literature. Plast Reconstr Surg, 111(1), 469-482.

Civitci, A. (2015). Perceived stress and life satisfaction in college students: Belonging and extracurricular participation as moderators. Procedia Soc Behav Sci, 205, 271-281.

Diener, E., Emmons, R. A., Larsen, R. J., \& Griffin, S. (1985). The satisfaction with life scale. J Pers Assess, 49(1), 71 75.

Durak, M., Senol-Durak, E., \& Gencoz, T. (2010). Psychometric properties of the satisfaction with life scale among Turkish university students, correctional officers, and elderly adults. Soc Indic Res, 99(3), 413-429.

Ebrahimzadeh, M. H., Moradi, A., Bozorgnia, S., \& HallajMoghaddam, M. (2016). Evaluation of disabilities and activities of daily living of war-related bilateral lower extremity amputees. Prosthet Orthot Int, 40(1), 51-57.

Gilg, A. C. (2016). The Impact of Amputation on Body Image. Honors College of The University of Southern Mississippi.

Holzer, L. A., Sevelda, F., Fraberger, G., Bluder, O., Kickinger, W., \& Holzer, G. (2014). Body image and selfesteem in lower-limb amputees. PLoS One, 9(3), e92943.

Hovardaoğlu, S. (1993). Vücut algısı ölçeği. Psikiyatri, Psikoloji, Psikofarmakoloji (3P) Dergisi, 1(1), 26.

Mayer, A., Kudar, K., Bretz, K., \& Tihanyi, J. (2008). Body schema and body awareness of amputees. Prosthet Orthot Int, 32(3), 363-382.

Miller, W. C., Deathe, A. B., \& Speechley, M. (2001). Lower extremity prosthetic mobility: a comparison of 3 selfreport scales. Arch Phys Med Rehabil, 82(10), 14321440.

Novotny, M. P. (1986). Body Image Change in Amputee Children: How Nursing Theory Can Make the Difference. Journal of the Association of Pediatric Oncology Nurses, 3(2), 8-13.

Pedlow, H., Cormier, A., Provost, M., Bailey, S., Balboul, G., Coucill, A., et al. (2014). Patient perspectives on information needs for amputation secondary to vascular surgery: What, when, why, and how much? Journal of Vascular Nursing, 32(3), 88-98.

Peroni, F., Cornaggia, C., Cerri, C., \& Perin, C. (2017). Distortion of Body Image Following Lower Limb Amputation: Implications for Comprehensive Rehabilitation. Current Advances in Neurology and Neurological Disorders, 1, 5-10.

Pirowska, A., Wloch, T., Nowobilski, R., Plaszewski, M., Hocini, A., \& Ménager, D. (2014). Phantom phenomena and body scheme after limb amputation: a literature review. Neurologia i neurochirurgia polska, 48(1), 52-59.

Safaz, I., Yilmaz, B., Goktepe, A. S., \& Yazicioglu, K. (2010). Turkish version of the amputee body image scale and relationship with quality of life. Klinik Psikofarmakoloji Bülteni-Bulletin of Clinical Psychopharmacology, 20(1), 79-83.

Shields, C., Thorp, H., Hendry, G., \& Jayakaran, P. (2015). Health-related quality of life in persons with dysvascular and traumatic lower limb amputation-a systematic review. Physiotherapy, 101, e673.

Sinha, R., \& Van Den Heuvel, W. J. (2011). A systematic literature review of quality of life in lower limb amputees. Disabil Rehabil, 33(11), 883-899.
Thompson, J. K., Heinberg, L. J., Altabe, M., \& Tantleff-Dunn, S. (1999). Exacting beauty: Theory, assessment, and treatment of body image disturbance: American Psychological Association.

Tylka, T. L., \& Wood-Barcalow, N. L. (2015). What is and what is not positive body image? Conceptual foundations and construct definition. Body Image, 14, 118-129.

Ülker Tümlü, G., \& Recepoğlu, E. (2013). Üniversite Akademik Personelinin Psikolojik Dayanıklılık ve Yaşam Doyumu Arasındaki İlişki. Journal of Higher Education \& Science/Yüksekögretim ve Bilim Dergisi, 3(3), 205-213.

Wetterhahn, K. A., Hanson, C., \& Levy, C. E. (2002). Effect of participation in physical activity on body image of amputees. Am J Phys Med Rehabil, 81(3), 194-201.

World Health Organization. (2001). International Classification of Functioning, Disability and Health: ICF: World Health Organization.

Zidarov, D., Swaine, B., \& Gauthier-Gagnon, C. (2009). Life habits and prosthetic profile of persons with lower-limb amputation during rehabilitation and at 3-month followup. Arch Phys Med Rehabil, 90(11), 1953-1959. 
